\title{
Dil, Söz ve Fesâhat: Abdülkâhir el-Cürcânînin Sözdizimi Nazariyesi
}

M. Taha Boyalık

İstanbul: Klasik Yayınları, 2017, 264 sayfa.

ISBN 9786055245979

Antik Yunan ve Ortaçağ Batı felsefesine göz atıldığında, dil olgusuna dönük felsefî soruşturmaların metafizik problemlerin bir parçası olarak yürütüldügü görülmektedir. Ancak Immanuel Kant’nn (ö. 1804) geleneksel metafizik eleştirileri ve sonrasında Gottlob Frege (ö. 1925) ve Bertrand Russell (ö. 1970) gibi isimlerin aritmetik ve mantık çalışmalarıyla birlikte durum değişmiştir. XIX. yüzyılın sonlarında "dile dönüş" (linguistic turn) deyiminde kendisini bulan ve geleneksel metafizik ve epistemolojiden kopup dile doğru radikal bir hareketi ifade eden yöneliş ortaya çıkmış ve bu süreçte dil felsefesi olarak bilinen alan teşekkül etmiştir. Böylece dil, müstakil bir varlık alanı olarak yeniden keşfedilerek varlık ve bilgi felsefesinin temel tartışmaları büyük oranda dil felsefesi bünyesinde yürütülmeye başlamıştır.

İslâm düşüncesine gelindiğinde, Batı'daki gibi dil felsefesi adıyla müstakil bir alan ortaya çıkmasa da bu, müslümanların dil üzerine felsefî soruşturmalar yapmadığı anlamına gelmemektedir. Yaptıkları varlık mertebeleri taksiminde dile müstakil bir varlık alanı açan müslüman düşünürler en başından beri dil gerçekliğinin farkındaydılar. Nitekim ilk asırlardan itibaren müslüman düşünürler tarafından dil ve dilin kullanımı üzerine felsefî soruşturmaların başladığı bilinmektedir. Daha detaylı araştırmalara ihtiyaç duymakla birlikte, ilk dönemde dil olgusu üzerine daha çok nahiv, edebî eleştiri ve kelâm geleneklerinde soruşturmalar yapıldığı, daha sonra fıkıh usulü ve mantık geleneklerini de içine alacak şekilde farklı alanlara uzanarak genişleyip geliştiği söylenebilir. Nahiv geleneği söz konusu olduğunda cümle seviyesindeki dil olgularını açıklamak üzere geliştirilen âmil ve i'rab nazariyeleri öne çıarken, ilâhî sıfatlar düzleminde sözün hakikati meselesi de kelâm tartışmalarında önemli yer tutmuştur. Yine bu olgu Fahreddin er-Râzînin (ö. 606/1210) fikıh usulü eseri olan el-Mahsûl'de geniş yer tutan dilsel uzlaşımın keyfiyeti ( $\mathrm{vaz}$ ), lafızların anlamlarına delâlet şekilleri ve farklı kullanım durumlarına dair bahisler ile İbn Sînâ ile (ö. 428/1037) birlikte mantık sistematiğinin başına yerleştirilen delâlet bahisleri üzerinden takip edilebilmektedir. VI. (XII.) asırdan sonra daha ziyade belâgat geleneğinde varlığını sürdüren dil felsefesi çalışmaları, Osmanlı döneminde 
müstakil bir disiplin olarak tesis edilen vaz' ilmiyle yetkin ürünlerini vermiştir. Bunlardan bağımsız olarak, Filibeli Seyyid Halil Efendi’nin (ö. 1301/1884) belâgatle ilgili eseri Hâş̧iye-i Cedîde'sine kısaca göz atmak bile İslâm düşüncesinde dil felsefesi çalışmalarının belâgat çerçevesinde ulaşt1$\breve{g}_{1}$ boyutları gözler önüne serecektir. Ne var ki, muhtelif alanlarda yapılan bu çalışmalar henüz hak ettiği ilgiyi göremediğinden, hâlâ gün yüzüne ç1karılmayı beklemektedir.

Günümüze kadar devam eden bu süreçte dil felsefesi çalışmaları için dönüm noktası ise, hicrî V. (XI.) asırda Abdülkāhir el-Cürcânî (ö. 471/1078-79) tarafından söz dizimi nazariyesinin (nazm) ortaya konulmasıyla olmuştur. Cürcânîden önceki dönemde dil üzerine konuşan bilim çevreleri kendi uzmanlık alanları çerçevesinde bilgi üretirken, dolaylı olarak dil felsefesi konularına değiniyorlardı. Ancak Cürcânî dili merkeze alarak doğrudan dil olgusu üzerine bir nazariye ortaya koymuş ve bir anlamda İslâm bilim tarihinde dil felsefesi çalışmalarının temelini atmıştır.

Kısaca ifade etmek gerekirse söz dizimi, Cürcânînnin ifadesiyle, gramatik anlamlar (meanin-nahv) gözetilerek kelimelerin bir araya getirilmesidir. ${ }^{1}$ Ancak dizim ile kastedilenin salt lafızların bir araya getirilmesinden ibaret olmadığı, söz telifinin dil, düşünce ve varlık ilişkilerine dair uzanımları olan çok boyutlu bir işlem olduğu hatırlatılmalıdır. İşte Cürcânînin bu süreç ve boyutlara yönelik yaptığı tahlillerin toplamı, söz dizimi nazariyesi olarak isimlendirilebilir.

"Söz dizimi" kavramında olduğu gibi, düşünce ve bilim tarihine yön veren kavramlar anlamlarını farklı zeminlerden devraldıkları problemleri bünyelerinde çözüme kavuşturmak suretiyle kazanmaktadırlar. Dolayısıyla bir kavram incelemesi, tarihsel arka planının ortaya konulması ve kavramsal haritasının çıkarılmasını talep etmektedir. Zorluklar barındıran bu arka plan tahlillerinin söz dizimi nazariyesi üzerine yapılan çağdaş çalışmaların arzu edilen yetkinlikte olmayışına etki ettiğini söylemek mümkündür. Nitekim nazariye üzerine yapılan çalışmalar ve Cürcânînin teorisi hakkında müstakil bir araştırma kaleme alan Ziyâeddin Fâzıl el-Hüseynî, hâlihazırdaki literatürün söz dizimi nazariyesinin tarihsel ve kavramsal çerçevesinin bilimsel şekilde doğru, tutarlı ve tam bir sunumunu yapmakta yetersiz kaldığını tespit etmektedir. ${ }^{2}$ Diğer yandan Cürcânînin özgün bir nazariye ortaya koymadığı, Yunan retoriğinin etkisinde kaldığ 1 ve belâgat çalışmalarında donuklaşma dönemini başlattığı şeklindeki bazı genellemeci ve indirgemeci yaklaşımlar

1 Abdülkāhir el-Cürcânî, Delâilü'l-i'câz, s. 81, 361.

2 Hüseynî, Urûzu nazariyyetin-nazm, s. 127-217. 
da nazariyenin anlaşılabilmesi önünde engel oluşturmaktadır. ${ }^{3}$ Türkiye'de söz dizimi nazariyesi üzerine kitap düzeyinde burada sunacağımız eserle birlikte yalnızca iki çalışma yapılmış olması ${ }^{4}$ ve makale düzeyindeki çalışmalarda ise daha çok geçtiğimiz yüzyılın sonlarında Arap dünyasında kaleme alınan belâgat tarihi eserlerinin esas alınmış olması, durumun ülkemizdeki akademik camia için de farklı olmadığını göstermektedir.

İstanbul 29 Mayıs Üniversitesinde öğretim üyesi olarak çalışmalarını sürdüren Yrd.Doç.Dr. M. Taha Boyalık’n kaleme aldığı Dil, Söz ve Fesâhat: Abdülkâhir el-Cürcânînin Sözdizimi Nazariyesi başlıklı eser, İslâm dil felsefesi birikiminin açığa çıkarılması noktasındaki eksikliği gidermeye yönelik önemli ve umut verici bir adım olarak değerlendirilebilir. İki bölüm olarak kaleme alınan eser, Boyalık’n Marmara Üniversitesi’nde hazırladığı "Abdülkâhir el-Cürcânînin Sözdizimi Nazariyesi ve Tefsir Geleneğine Etkisi" başlıklı doktora tezinin söz dizimini ele alan ilk bölümünün yeniden düzenlenmiş ve geliştirilmiş halinden ibarettir. “Giriş”te Abdülkāhir el-Cürcânînin hayat hikâyesi düşünsel kimliğinin oluşumuyla irtibatlı olarak öz şekilde verilmiş, "Sözdizimi Nazariyesini Hazırlayan Tartışma ve Bilim Gelenekleri” başlıklı birinci bölümde söz dizimi nazariyesinin tarihsel arka planı ortaya konulmuş, "Sözdizimi Nazariyesinin Dilbilimsel, Felsefî ve Edebî Boyutları" başlıklı ikinci bölümde konunun kavramsal boyutları açığa çıkarılmış, "sonuç" bölümünde ise çalışmada savunulan temel tezler sıralanarak eser nihayete erdirilmiştir.

Boyalık’n temel iddiası, söz dizimi nazariyesinin; sözün fesahati ve îcazını tutarlı bir şekilde açıklamak üzere geliştirilen, fakat özü itibariyle, dilin ve sözün mahiyeti meselesine çözüm getiren bir nazariye olduğudur (s. 24). Yazarın bu düşüncesi, eserin başlı̆̆ ve muhtevasına da yansımıştır. Gerçekten de, söz dizimi nazariyesinin ortaya konulduğu Delâilül-i'câz’a göz atıldığında, ilk etapta bir belâgat ve îcaz eseri olarak görülecektir. Eserde sistematik bir yazım tarzından ziyade serbest bir yazım tarzının takip edilmesi ve îcaz ile söz dizimi kavramlarının öne çıkarılması bu kanaatin oluşmasına zemin hazırlamaktadır. Ancak Boyalık, Delâil'i mantıksal kurgusu içerisinde farklı bir okumaya tâbi tutarak, eserdeki dilin ve sözün mahiyetiyle ilgili çözümlemelerin "söz dizimi” kavramını temellendirmede kullanıldığı, "söz dizimi” ile "fesahat" kavramlarının temellendirildiği ve "fesahat" ile de "icâz" kavramlarının temellendirdiğini öne sürmektedir (s. 118).

3 Meselâ bk. Tâhâ Hüseyin, "Arap Belâgati: el-Câhiz'den Abdu'l-Kâhir'e Kadarki Süreç", çev. Zafer Kızıklı, Ankara Üniversitesi İlâhiyat Fakültesi Dergisi, 51/2 (2010): 433-60.

4 Diğeri; Sedat Şensoy, "Abdülkâhir el-Cürcânîde Anlam Problemi” (doktora tezi), Marmara Üniversitesi Sosyal Bilimler Enstitüsü, 2001. 
Dil, Söz ve Fesâhat' in ilk bölümünde nazariyenin tarihsel uzanımları ve yeşerdiği çevreyle olan ilişki ağları açığa çıkarılmaktadır. Buna göre söz dizimi nazariyesi nahiv, mantık, kelâm, edebî eleştiri, belâgat ve îcaz geleneklerindeki tartışmalardan beslenmiştir.

Söz dizimi nazariyesinin beslendiği ilk ve belki de en önemli kaynak nahiv geleneğidir. Abdülkāhir el-Cürcânî, bir yandan nahiv geleneğinden devraldığı zengin birikimi nazariyesini temellendirirken kullanmış, öte yandan nahivcilerle mantıkçılar arasındaki cümle yapısının mantıksal statüsüne dair tartı̧̧malara eklemlemiştir. Mantıkçı Mettâ b. Yûnus (ö. 328/940) ile nahivci Ebû Saîd es-Sîrâfì (ö. 368/979) arasında geçen tartışmada Mettẩnın, mantığın evrensel anlamlarla nahvin ise belirli bir dilin lafızları ile ilgilendiği iddiası karşısında Sîrâfí, "nahvin anlamları" kavramını öne sürerek Mettẩnın iddialarını çürütmeye çalışmaktadır. Cürcânî eserlerinde bu tartışmaya bir atıfta bulunmamaktadır. Bununla birlikte Boyalık, aynı zamanda iyi bir dil bilimci olan ve bilim kariyerinin ilk dönemini nahiv çalışmalarına ayıran Cürcânînin nahiv alanındaki çalışmalarına da başvurarak söz dizimi ile nahiv-mantık tartışmaları arasındaki irtibatı ortaya koymayı denemektedir. Buna göre, nahiv çalışmalarındaki "Îrap anlamdadır" söylemi ile ilk defa Sîrâfî tarafından kullanıldığ 1 bilinen "nahvin anlamları" kavramını Delâil'de buluşturan Cürcânî, mantıkçllar karşısında nahivciler tarafında yer almıştır. Bu noktada Boyalık, i'tizâlî söz anlayışının bir çelişkisini de açığa çıarmaktadır. Şöyle ki, mantıkçlar karşısında nahiv savunusuna doğal olarak eklemlenen nahivcilerin başta Sîrâfî olmak üzere önde gelenlerinin Mútezile’yi benimsedikleri bilinmektedir. Ne var ki, fesahati anlamlara atıfla açılamak bir zihni söz varlığını gerektireceğinden Mu'tezilî düşünürler fesahati, genelde lafızlara atıfla açıklama yoluna gitmişlerdir. Ancak mantık-nahiv tartışmaları bağlamında düşünüldügünde, onların bu lafızcı fesahat anlayışının mantıkçıların iddialarını desteklediği görülecektir. Bir anlamda onlar, ilâhî söz düzleminde savundukları yaratılmış söz anlayışından tâviz vermemek adına, beşerî söz düzleminde lafızcı bir fesahat anlayışını benimsemişlerdir. Boyalık açtığ 1 müstakil bir başlık üzerinden ve eserin çeşitli yerlerinde, yaratılmış ilâhî söz anlayışını savunanların, beşerî sözün hakikatine dair söylemlerinde sürekli bir çelişkiye düştüklerini dillendirmektedir (s. 69, 138-139). Şu durumda Cürcânînin lafızcı fesahat anlayışına yönelttiği sert eleștiriler ve zihnî söz varlığına yaptığı vurgular, ítizâlî söz anlayışına dil düzleminden getirilmiş en etkili tenkitlerden biri olmuştur (s. 28). ${ }^{5}$

5 Söz dizimi nazariyesi bağlamında yaratılmış söz anlayışının daha ayrıntılı bir eleştirisi için şu makaleye bakılabilir: Taha Boyalık, "Kādî Abdülcebbâr’nn 'Sözün Hakikati 
Boyalık nahiv ve kelâm geleneklerinin ardından, edebî eleştiri ve belâgat geleneğini söz dizimi nazariyesinin beslendiği bir diğer kaynak olarak tespit eder. Burada, Cürcânî öncesindeki fesahat araştırmalarında lafız-anlam ikiliğinin hâkim olduğu ve fesahatin genellikle lafızlara atıfla açıklandığı gösterilerek süreç Cürcânîye kadar getirilmiştir. Cürcânînin lafız-anlam problemine yönelik sunduğu yeni kavramsal çerçeve ise eserin ikinci bölümünün ikinci başlığında ortaya konulmaktadır.

Eserde îcaz mektebi söz dizimi nazariyesinin beslendiği son kaynak olarak tespit edilir. Kelâmcılarla edebiyatçıların ortak meselesi olan Kur'an’ın îcazı, Cürcânînin de gündemindedir. Onun ortaya koyduğu söz dizimi, her ne kadar sadece bir îcaz nazariyesi değilse de, nazariyenin çıkış noktası ve muharrik gücü Kur’an’ın îcazının mâkul bir şekilde açıklanması olmuştur. Bu başlikta îcaz literatüründe kaleme alınan eserlerde söz dizimi kavramının izleri sürülerek, bir îcaz vechi olarak söz diziminin Cürcânîden önce kimi düşünürler tarafından dillendirilse de, belirli belirsiz kullanıldığ ve bilimsel bir temellendirilmesinin sunulmadığ 1 gösterilmektedir (s. 99-111). Bu başlık ve eserin ikinci bölümünde açığa çıkarılan veriler, çağdaş bazı araştırmacıların söz dizimi nazariyesinin Cürcânîden önce Kādî Abdülcebbâr (ö. 415/1025) tarafindan muhteva olarak ortaya konulduğunu, Cürcânînin yaptığının ise nazariyenin adını koymaktan ibaret olduğu yönündeki iddialarının doğruluk ve tutarlılık payını da gösterir mahiyettedir.

Dil, Söz ve Fesâhat' in ilk bölümünde, söz dizimi nazariyesini karşıtlıklar ve birliktelikler üzerinden besleyen tartı̧̧ma ve bilim gelenekleri nazariyeyle ilgili oldukları ölçüde ortaya konulduktan sonra, "Sözdizimi Nazariyesinin Dilbilimsel, Felsefî ve Edebî Boyutları” başlıklı ikinci bölümde, söz dizimi kavramı derinlemesine bir incelemeye tâbi tutulmaktadır. Söz dizimi nazariyesinin dil bilimi ve felsefî boyutlarının serimlendiği bu bölüm, söz dizimi üzerine yapılan diğer çalışmalarla kıyaslandığında, eserin en özgün sayfalarını oluşturmaktadır. Burası okunmadan önce ve sonra Delâil ve Esrâr okunduğu takdirde bizce, Boyalık’ın bu noktadaki ince işçiliği takdir edilecektir. Zira Cürcânînnin bahsi geçen iki eseri de, sistematik değil serbest bir yazım tarzının takip edildiği eserlerdir ve yüzeysel bir okuma, her iki eseri de edebî birer metin olmaktan ileri götürmeyecektir.

Yazarın eserde, Cürcânînin "nazm" lafzı ile ifade ettiği kavramı "söz dizimi” ile karşılamış olması okuyucuyu, nazariyenin dilin gramatik yapısıyla (sentaks) sınırlı olduğu zannına götürmemelidir. Boyalık söz dizimi kavramını

Teorisi' ve Abdülkāhir el-Cürcânînin 'Sözdizimi Teorisi' Bağlamında Bir Eleștirisi”, İslâm Araştırmaları Dergisi, 28 (2012): 61-84. 
dilin kullanım boyutuyla (pragmatik) anlam boyutunu da (semantik) içine alacak şekilde kullanmaktadır. Nitekim söz dizimi nazariyesinin eserde açığa çıkarılan eklektik yapısı da bunu göstermektedir.

Bu bölümü "Dilbilimsel ve Felsefî Açıdan Sözdizimi" ve "Edebî Açıdan Sözdizimi” şeklinde iki kısma ayıran Boyalık, söz diziminin esasında bir dil nazariyesi olduğu düşüncesine binaen, söz dizimini dil bilimi ve felsefe açısından ele alacağı başlığı, edebî açıdan incelediği başlığa öncelemektedir.

Boyalık ilk başlık altında, Cürcânînin Delâil ve Esrâr'da satır aralarına dağınık olarak iliştirdiği dilin ve sözün mahiyetine dair tahlilleri sistemli bir şekilde değerlendirerek, söz dizimi nazariyesinin dil-söz, dil-zihin, dildüşünce ve dil-dünya ilişkilerine dair neler söylediğini ortaya koymaktadır.

Mantıkçıların ve Mưtezile kelâmcılarının araçsal dil tasavvurlarının aksine Cürcânî, dili bir yapı olarak kavramıştır. O, bireysel müdahalelere kapalı "dil" ile bireylerin kullanımlarında açığa çıkan "söz" arasında bir ayırıma giderek, dil kullanıcısı bireyin fiillerinden bağımsız kendine yeter bir dil varlığına dikkat çekmektedir. Bu ayırım gözetildiğinde, Boyalık’n ifadesiyle "söz dizimi nazariyesi dil bilimi ve felsefî yönüyle 'dil'e, edebî yönüyle ise 'söz’e ait bir inceleme" olarak kendini göstermektedir (s. 125).

Cürcânî dil-söz ayrımında dil ile doğal dilleri kastetmekle birlikte, dil gerçekliğinin özsel varllğıyla da ilgilenmektedir. Cürcânînin dil-zihindüşünce ilişkisine dair tahlilleri yazar tarafından "anlamın lafza ontik önceliği", "gramerin zihnîliği" ve "anlamın gramatikliği" şeklinde kavramsallaşt1rılarak "Dil ve Zihin" ve "Dil-Düşünce İlişkisi” başlıkları altında okuyucuya sunulmaktadır. Burada, söze zihinde bir gerçeklik atfetmemenin yol açacağ1 dilin araçsallaştırılması tehlikesine karşı Cürcânînin dil-zihin-düşünce bağını nasıl ördüğg̈ gösterilmektedir. Özellikle bu iki başlık, Cürcânînnin grameri asırlar öncesinden bir zihin olgusu olarak kavradığı ve gramerin kültürcü değil doğalcı bir açılklamasını verdiğinin müdellel hale getirildiği sayfalardır.

Çağdaş dönemde canlı bir tartışma konusu olan anlamın gönderimi probleminin de söz dizimi nazariyesinde kendine yer edindiği görülür. Boyalık "Dil-Dünya İlişkisi" başlı̆̆ı altında, Cürcânînin isim vermeden eleştirdiği Kādî Abdülcebbâr’’n mütekabiliyetçi dil anlayışına karşılık, dili kendi dünyası içinde kavrayan söz dizimi nazariyesini öne çıarmaktadır. Bu başlıkta Cürcânînin, haberin doğruluk değeri ile (doğru-yanlış) dildeki delâletini (anlamlı-anlamsız) nasıl ayrıştırdığı, yapılan ince tahlillerle anlatılarak bir anlamda mütekabiliyetçi dil anlayışının açmazları ortaya konulmaktadır. 
Boyalık Cürcânînnin dilsel ve dışsal varlık seviyelerini nasıl ayrıştırdığını gösterdikten sonra, söz dizimi nazariyesinin dilin kullanımı ve dilin kendi dünyasına dair neler söylediğini ortaya koymaktadır. Bu amaçla açılan "Dilin Kullanımı ve Dilin Dünyası" başlığında, daha sonra dil çalışmaları ve belâgat literatüründe ayrıntılı olarak incelenecek olan "ifade", "kullanım", "bağlam" gibi temel kavramlar söz dizimi nazariyesi bünyesinde incelenmektedir.

Söz dizimi nazariyesinin düşünsel arka planı böylece ortaya konulduktan sonra, nazariyenin dilin kullanıma dönük boyutuyla ilgili neler söylediğini ortaya koymak, eser boyunca yapılan sunumların ürünlerini toplamak mesabesinde olacaktır. Eserin ikinci bölümünün ikinci başlı̆̆ı olan "Edebî Açıdan Sözdizimi Nazariyesi”, Cürcânînnin dile ve dilin kullanımına dair yaptığ1 tahlillerin edebî tenkit ve belâgat geleneğindeki yansımalarını incelemektedir. Belirtildiği üzere Cürcânî, söz dizimi nazariyesini nahiv ile doğrudan irtibatlı şekilde geliştirmiştir. Bu noktada sözün dil bilgiselliği ile ilgilenen nahiv ile edebî değeriyle ilgilenen belâgatın arasını ayırmak ve birbirleriyle ilişkisini göstermek önem kazanmaktadır. Boyalık’n bu başlıktaki hedeflerinden biri bu ilişkinin açığa çıkarılmasıdır (s. 199-206). Doğrudan belâgat düzleminde düşünüldüğünde, söz dizimi uygulamaları ile dolaylamalı anlatımlar arasındaki hiyerarşik ilişkinin tespiti de bu başlığın çözmeyi hedeflediği meselelerdendir (s. 207-209). Öte yandan söz dizimi nazariyesinin nihaî çerçevesini, sistemli bir yazım tarzından ziyade sorgulayıcı bir yazım tarzı benimsendiği için Delâil in sona ermesiyle birlikte kazandığı belirtilmelidir. $\mathrm{Bu}$ sebeple, Delâil'in yazım sürecinde kimi çelişik beyanlara da rastlanmaktadır. Boyalık’ın bu tür çelişkileri gidermek için yaptığı yorumların açıklama gücü ise okuyucunun takdirindedir (s. 207-209, 220-223).

Dil, Söz ve Fesâhat metin ve kavram örgüsünün açık ve sağlam olması, diğer çalışmalarda Cürcânî düşüncesiyle ilgili ileri sürülen tezlerin müdellel hale getirilmesi, Cürcânînin yazdığ̣ eserlerin tamamının kaynak olarak alınması ${ }^{6}$ konuya uzak okuyucu için terimlerin anlaşılır şekilde ifade edilmesi, çağdaş dil felsefesi çalışmalarıyla indirgemeci mukayeselere gidilmeyerek nazariyenin kendi bağlamında ortaya konulması açısından önemli bir kaynak olarak değerlendirilmelidir. Bu anlamda eser sadece Cürcânî ve belâgat araştırmacılarının değil, genel olarak dil felsefesine ilgi duyan okuyucuların da ilgisini hak etmektedir.

6 Meselâ söz diziminin gramatik boyutlarını inceleyen bir çalışmada Cürcânînin nahivle ilgili hiçbir eserine başvurulmamıştır (bk. Fuad Ali Muhaymir, Felsefetü Abdilkāhir elCürcânî en-nahviyye fî Delâili’l-iccâz, Kahire: Dârü’s-sekāfe, 1983). Boyalık Cürcânînin nahiv çalışmalarını temel kaynakları arasına almıştır. Öte yandan Boyalık’n, Cürcânî düşüncesi üzerine yapılan çağdaş çalışmalara nâdiren atıfta bulunduğu görülmektedir. 
Şüphesiz söz dizimi nazariyesi üzerine daha detaylı çalışmalara ihtiyaç vardır. Buna ek olarak, Cürcânî sonrasında nazariyenin nasıl bir değişim geçirdiği ve hangi alanlarda ne gibi tesirler bıraktığı hâlâ açığa çıkarılmayı beklemektedir. İlk olarak Fahreddin er-Râzînin, nazariyenin felsefî boyutlarını belli ölçüde göz ardı ederek, nazariyeyi bir belâgat dalı olarak kurguladığ ve bu sürecin Ebû Ya'kūb es-Sekkâkî (ö. 626/1229) ve Hatîb el-Kazvînî (ö. 739/1338) elinde tamamlandığı söylenebilir. Ancak Râzî ve Sekkâkînin söz dizimi anlayışları üzerine yeterli çalışmaların yapılmamış olması sebebiyle bu yargı tahkike muhtaçtır. Bununla irtibatlı olarak, söz dizimi nazariyesinin niçin felsefî bir nazariye olmaktan çok bir belâgat nazariyesi olarak varlığını sürdürdügü sorusu da cevap beklemektedir. Bunun sebebi, dile dönüşün varlıktan kopuşa yol açacağı kaygısı olabilir mi? Soruyu bir başka şekilde sormak gerekirse, Batı’da dil felsefesi çalışmalarının geçirdiği süreç, niçin İslâm düşüncesi söz konusu olduğunda farklılaşmaktadır?

\title{
Bibliyografya
}

Abdülkāhir el-Cürcânî, Delâilüll-ícâz, nşr. Mahmûd M. Şakir, Kahire: Mektebetü'lHancî, 1413/1992.

Hüseynî, Ziyâeddin Fâzıl, Urûzu nazariyyetìn-nazm inde'l-imâm Abdilkāhir elCürcânî ve mebâhisühâ, Amman: Ervika lìd-dirâsât ve’n-neşr, 1436/2015.

\author{
Ahmet Aytep, Arş.Gör. \\ İstanbul 29 Mayıs Üniversitesi \\ Uluslararası İslâm ve Din Bilimleri Fakültesi \\ ORCID 0000-0002-8508-0067 \\ DOI $10.26570 /$ isad.410186
}

